\title{
Susceptibility of shear banding to chemical short-range order in metallic glasses
}

\author{
Zeng-Yu Yang, Yun-Jiang Wang *, Lan-Hong Dai* \\ State Key Laboratory of Nonlinear Mechanics, Institute of Mechanics, Chinese Academy of Sciences, Beijing 100190, PR China \\ School of Engineering Science, University of Chinese Academy of Sciences, Beijing 101408, PR China
}

\section{A R T I C L E I N F O}

\section{Article history:}

Received 26 September 2018

Received in revised form 28 October 2018

Accepted 1 November 2018

Available online $\mathrm{xxxx}$

\section{Keywords:}

Metallic glasses

Shear bands

Chemical short-range order

Molecular dynamics

\begin{abstract}
A B S T R A C T
To clarify the critical role of chemical short-range order on the formation of shear bands in metallic glasses, atomistic simulations are performed on $\mathrm{Pd}_{82} \mathrm{Si}_{18}$ and $\mathrm{Cu}_{50} \mathrm{Zr}_{50}$ with different cooling history. It is found that shear bands are prone to form in samples with higher level of chemical short-range order. The magnitude of stress overshoot in shear stress-strain curve and the spatial fluctuation of short-range chemical composition are proposed to characterize shear banding susceptibility and chemical short-range order, respectively. A quantitative correlation is therefore established between shear banding and chemical short-range order. The microstructural origin of the correlation is discussed.
\end{abstract}

(c) 2018 Acta Materialia Inc. Published by Elsevier Ltd. All rights reserved.
In recent years, metallic glasses (MGs) have obtained massive attention due to their exceptional mechanical behaviors compared with their crystalline counterparts [1-4]. However, it is difficult to figure out the underlying mechanisms accommodating such unique mechanical properties such as outstanding strength, high elastic strain, high elastic energy storage capacity, and intrinsic size effect due to the disorders of structure and chemical composition in MGs [5-10]. A recent research [11] reported that chemical heterogeneity makes cavitation more difficult in $\mathrm{Pd}_{82} \mathrm{Si}_{18}$ than that in $\mathrm{Cu}_{54} \mathrm{Zr}_{46}$, resulting in higher toughness of $\mathrm{Pd}_{82} \mathrm{Si}_{18}$. However, how does the disorders of chemical composition influence the shear band formation in metallic glasses is unclear. As shear banding is an omnipresent phenomenon in metallic glasses especially at low temperature, and high stress or high strain rate conditions [12,13]. Highly localized plastic deformation always occurs in MGs, resulting in nanoscale shear bands $[14,15]$. Understanding the mechanism of the formation of shear bands is of vital importance in the context of materials science and condensed matter physics.

Many works $[16,17]$ have been done to explore the structural origin of shear bands in MGs and the common standpoint is that structural heterogeneity will cause solid-like and liquid-like regions [18-20] in MGs and these liquid-like regions, with lower atomic packing density, are more likely to become fertile regions of potential sheartransformation zones (STZs) [21-23]. Actually, the internal structure of an MG is inhomogeneous in terms of its variable chemical and topological short-range order (SRO) at atomic scale. Note that this heterogeneity is different from the usual structural heterogeneity on a larger

\footnotetext{
* Corresponding authors.

E-mail addresses: yjwang@imech.ac.cn (Y.-J. Wang), lhdai@lnm.imech.ac.cn (L.-H. Dai).
}

length scale, where the heterogeneity is the difference of "liquid-like" soft spots compared with the solid matrix. Thus, for a structure with multiple species, it is meaningful to analyze the chemical composition of the nearest neighbor, i.e., the degree of chemical short-range order (CSRO) [24]. The key question is whether such CSRO will also affect the formation of the general shear banding phenomenon. If so, what the correlation is and how the CSRO influences shear banding in MGs at atomic-scale.

In the present work, we design molecular dynamics (MD) simulations to gain insights into the relationship between the shear banding and CSRO in metallic glasses. To simplify simulation and analysis, we choose two distinct binary MGs for demonstration: one is $\mathrm{Cu}_{50} \mathrm{Zr}_{50}$, a typical metal-metal system in which metallic bonding dominates; and the other is $\mathrm{Pd}_{82} \mathrm{Si}_{18}$, a metal-metalloid alloy with plentiful chemical orders [25]. We introduce two parameters to quantify the shear banding susceptibility and level of CSRO, and propose a quantitative relationship between CSRO and the susceptibility of shear bands in glasses.

LAMMPS code [26] is used for the MD simulations. We use the embedded-atom method (EAM) potential [27] to describe the force field, which is developed to describe the atomic interactions for $\mathrm{Cu}_{50} \mathrm{Zr}_{50}$ and $\mathrm{Pd}_{82} \mathrm{Si}_{18}$ glasses. The samples are firstly melted from their crystalline phases from $100 \mathrm{~K}$ to $2100 \mathrm{~K}$, and then being equilibrated for $500 \mathrm{ps}$ at $2100 \mathrm{~K}$ before quenched into glassy state ( $100 \mathrm{~K}$ ) at different cooling rates of $0.02,0.2,2,20 \mathrm{~K} / \mathrm{ps}$ for both $\mathrm{Cu}_{50} \mathrm{Zr}_{50}$ and $\mathrm{Pd}_{82} \mathrm{Si}_{18}$. The variation in cooling rates is expected to induce different level of chemical and topological SRO in the glassy structures [28]. The pressure and temperature are monitored using isothermal-isobaric ( $N$ atom number, $P$ pressure, and $T$ temperature) ensembles [29] and Nosé-Hoover thermostat $[30,31]$. Periodic boundary condition is 
adopted for each direction during the sample preparation and shear deformation process. The MD time step is $1 \mathrm{fs}$. Altogether we obtain eight samples of 162,000 atoms, with dimensions of $\sim 17.5 \mathrm{~nm} \times 11.7 \mathrm{~nm}$ $\times 11.7 \mathrm{~nm}$ of $\mathrm{Pd}_{82} \mathrm{Si}_{18}$ and $\mathrm{Cu}_{50} \mathrm{Zr}_{50}$, at four different cooling rates. In the shear deformation, a strain rate of $10^{9} \mathrm{~s}^{-1}$ is applied in the $x y$ shear protocol at low temperature $100 \mathrm{~K}$, which is believed to facilitate shear banding in the atomic MG models.

We now present the results of MD shear tests. Firstly, the complete process from initial structure to shear band formation of $\mathrm{Cu}_{50} \mathrm{Zr}_{50}$ and $\mathrm{Pd}_{82} \mathrm{Si}_{18}$ under shear is given in Fig. $\mathrm{S} 1$. The color scheme is the local atomic von Mises shear strain $\eta^{\text {Mises }}[17,32]$. It is obvious that there are certain differences in the nucleation and evolution of shear bands in the two MG samples. Compared with $\mathrm{Cu}_{50} \mathrm{Zr}_{50}$, the $\mathrm{Pd}_{82} \mathrm{Si}_{18}$ samples are more susceptible to shear banding under the same conditions. In addition, it is revealed from Fig. $\mathrm{S} 1$ that the susceptibility of shear banding decreases with increasing cooling rates, which is consistent with our previous research [16].

Meanwhile, we present the shear stress-strain curves of the two MGs in four different cooling rates; see Fig. 1(b) and (c). Both the peak stress $\left(\tau_{\text {peak }}\right)$ and the flow stress $\left(\tau_{\text {flow }}\right.$ ) levels of $\mathrm{Pd}_{82} \mathrm{Si}_{18}$ are higher than those of $\mathrm{Cu}_{50} \mathrm{Zr}_{50}$, which is actually due to the different chemical bonding characteristics in the two systems. Some previous works $[33,34]$ have shown that $\tau_{\text {peak }}$ and $\tau_{\text {flow }}$ have specific physical meanings, in which $\tau_{\text {peak }}$ represents the intrinsic impediment to the initial flow of the MGs or the stress required for rejuvenation [18] under given loading conditions (i.e., strain rate, temperature, and/or loading history), while $\tau_{\text {flow }}$ represents the shear resistance of MGs after rejuvenation. Thus the difference between $\tau_{\text {peak }}$ and $\tau_{\text {flow }}, \Delta \tau=\tau_{\text {peak }}-\tau_{\text {flow }}$ (called stress overshoot in shear), which is mainly caused by the delayed activation of shear transformations due to the lack of free volume during the process of deformation, reveals the contrast of initial structure and that after rejuvenation. Thus it is also a measurement of the strain localization ability. Therefore, here we introduce $\Delta \tau=\tau_{\text {peak }}-$ $\tau_{\text {flow }}$ to quantitatively describe the susceptibility of shear banding in glasses. Higher $\Delta \tau$ means the system is more susceptible to shear banding and vice versa. The scheme is demonstrated in Fig. 1(a).

We supplement six MD simulations with more cooling rates to get more quantitative points between shear banding and stress overshoot. In Fig. 1(d), the correlation between stress overshoot and cooling rates is plotted, which suggests that $\Delta \tau$ (or the shear band susceptibility) decreases with increasing cooling rates in sample preparation for both $\mathrm{Cu}_{50} \mathrm{Zr}_{50}$ and $\mathrm{Pd}_{82} \mathrm{Si}_{18}$ glasses. In addition, the $\Delta \tau$ levels of $\mathrm{Pd}_{82} \mathrm{Si}_{18}$ are higher than those of $\mathrm{Cu}_{50} \mathrm{Zr}_{50}$ at the same conditions, which implies that the shear banding susceptibility of $\mathrm{Pd}_{82} \mathrm{Si}_{18}$ is more significant than $\mathrm{Cu}_{50} \mathrm{Zr}_{50}$, which is consistent with the information extracted from deformation patterns shown in Fig. S1.

Here we explain the aforementioned phenomenon that CSRO plays an important role on shear banding in MGs. There is significant difference in the chemical composition and their spatial distribution between $\mathrm{Cu}_{50} \mathrm{Zr}_{50}$, the typical metal-metal glasses, and $\mathrm{Pd}_{82} \mathrm{Si}_{18}$, which is a representative metal-metalloid system. The nature of chemical bonding is quite different in $\mathrm{Pd}_{82} \mathrm{Si}_{18}$ and $\mathrm{Cu}_{50} \mathrm{Zr}_{50}$. In $\mathrm{Pd}_{82} \mathrm{Si}_{18}$, Pd-Pd form metallic bonds, while $\mathrm{Pd}-\mathrm{Si}$ and $\mathrm{Si}-\mathrm{Si}$ form covalent or covalent-like bonds. However, in $\mathrm{Cu}_{50} \mathrm{Zr}_{50}$, all of $\mathrm{Cu}-\mathrm{Cu}, \mathrm{Cu}-\mathrm{Zr}$ and $\mathrm{Zr}-\mathrm{Zr}$ form metallic bonds. Obviously, this significant difference in bonding may result in different spatial distribution of chemical elements in the two systems. We count the surrounding chemical environments (including the nearest neighbor atoms) of all $\mathrm{Cu}, \mathrm{Zr}$, Pd and $\mathrm{Si}$ atoms in the two systems. The results, summarized in Table S1, indicate that the distribution of chemical elements is uneven in both $\mathrm{Cu}_{50} \mathrm{Zr}_{50}$ and $\mathrm{Pd}_{82} \mathrm{Si}_{18}$. But the degree of CSRO in $\mathrm{Pd}_{82} \mathrm{Si}_{18}$ is more significant than that in $\mathrm{Cu}_{50} \mathrm{Zr}_{50}$. For example, the surrounding chemical environment of Pd atoms is quite different from $\mathrm{Si}$ atoms in $\mathrm{Pd}_{82} \mathrm{Si}_{18}$, while this phenomenon is not such obvious between $\mathrm{Cu}$ and $\mathrm{Zr}$ atoms in $\mathrm{Cu}_{50} \mathrm{Zr}_{50}$.

To clarify the relationship between CSRO and shear banding, we propose a universal strategy based on the spatial fluctuation of chemical
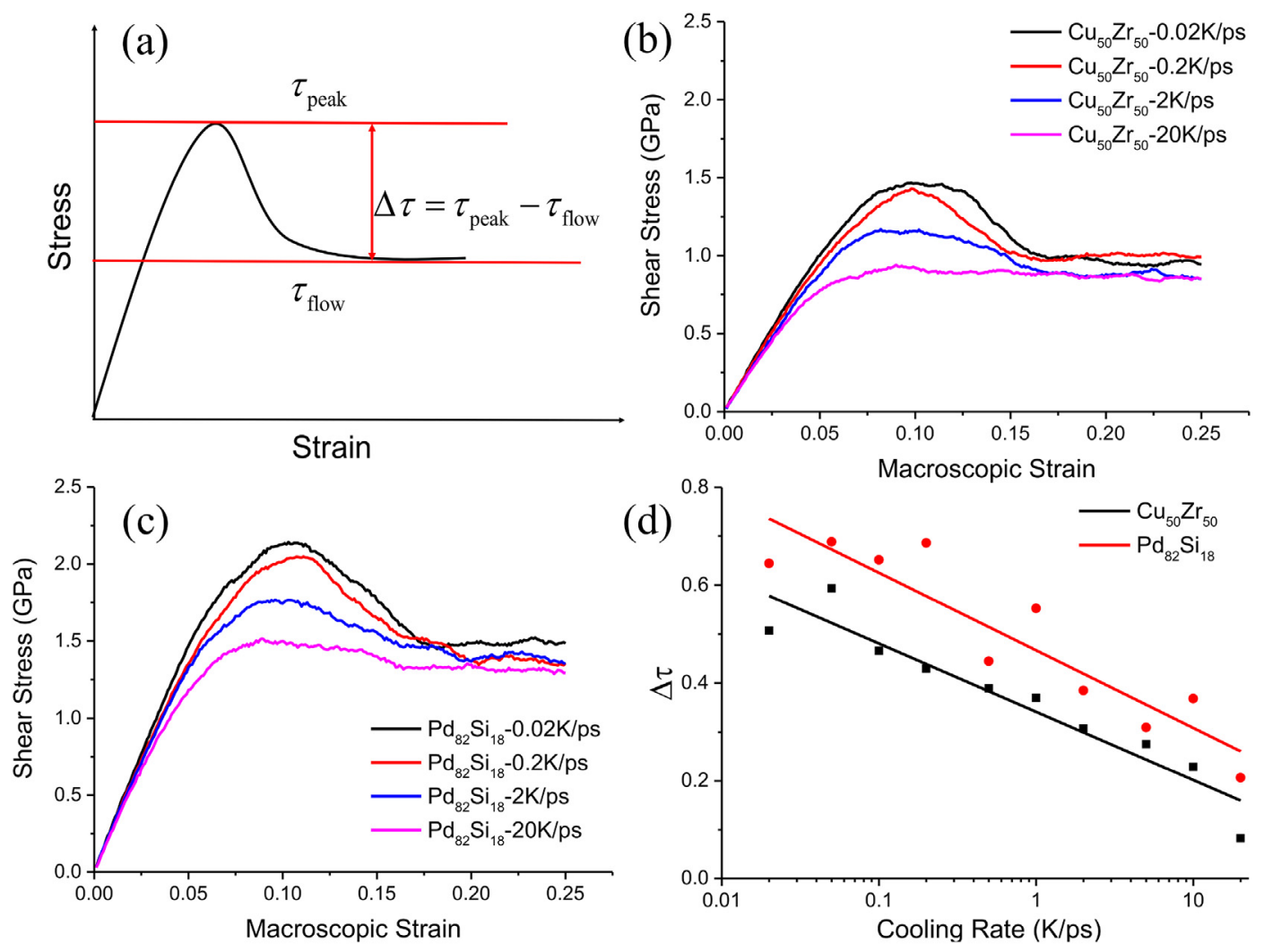

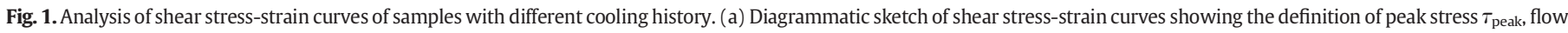

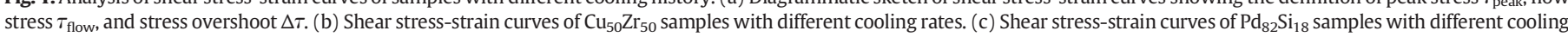
rates. (d) The magnitude of shear stress overshoot, $\Delta \tau=\tau_{\text {peak }}-\tau_{\text {flow, }}$ as a function of cooling rates. 
composition to quantitatively characterize the CSRO of a multicomponent glassy structure. First of all, we define a parameter $X_{\alpha}^{i}$ as the composition fraction of $\alpha$ type atoms around the $i$-th atom (including the $i$-th atom) to describe the surrounding chemical environment. Here the cutoff distance of cluster around atom $i$ is chosen to be 3.75 $\AA$, which is corresponding to the position of the first valley in the radial distribution function (RDF) of the glass. It is therefore the chemical composition is coarse-grained in the short-range order. We calculate the mean of $X_{\alpha}^{i}$ for all atoms without distinguishing the atom types, i.e., $\bar{X}_{\alpha}$ $\left(\bar{X}_{\mathrm{Cu}}, \bar{X}_{\mathrm{Zr}}, \bar{X}_{\mathrm{Pd}}, \bar{X}_{\mathrm{Si}}\right)$ of the two systems under different cooling rates. The results shown in Fig. 2(a) and (b) indicate that all the $\bar{X}_{\alpha}$ s deviate from the macroscopic composition in both $\mathrm{Cu}_{50} \mathrm{Zr}_{50}$ and $\mathrm{Pd}_{82} \mathrm{Si}_{18}$ MGs. It means that CSRO is an intrinsic nature of MGs. The samples with high level of deviation in chemical composition are related to slow cooling rates. Therefore, well-aged glasses are usually corresponding to high level of CSRO. We further use the parameter $\bar{X}_{\alpha}$ to quantitatively characterize the CSRO in an advanced form,

$\chi=\frac{1}{n} \sum_{\alpha}^{n}\left|\bar{X}_{\alpha}-X_{\alpha}^{0}\right| / X_{\alpha}^{0}$

Eq. (1) determines the degree of CSRO in a glass system, where $\chi$ is the parameter of CSRO, $n$ is the number of element types (here $n=2$ ), and $X_{\alpha}^{0}$ is the macroscopic composition of $\alpha$ element. Obviously, the parameter $\chi$ is a dimensionless parameter that can quantify the degree of dispersion of the distribution of chemical elements in MGs. It can be used in the comparison between different systems and the same systems prepared with different cooling rates. Larger $\chi$ of a system means higher level of CSRO.

As for our binary metallic glasses, $n=2$, and the expression of CSRO is expanded as (taking $\mathrm{Pd}_{82} \mathrm{Si}_{18}$ as an example)

$\chi=\frac{1}{2}\left[\left|\bar{X}_{\mathrm{Pd}}-X_{\mathrm{Pd}}^{0}\right| / X_{\mathrm{Pd}}^{0}+\left|\bar{X}_{\mathrm{Si}}-X_{\mathrm{Si}}^{0}\right| / X_{\mathrm{Si}}^{0}\right]$.
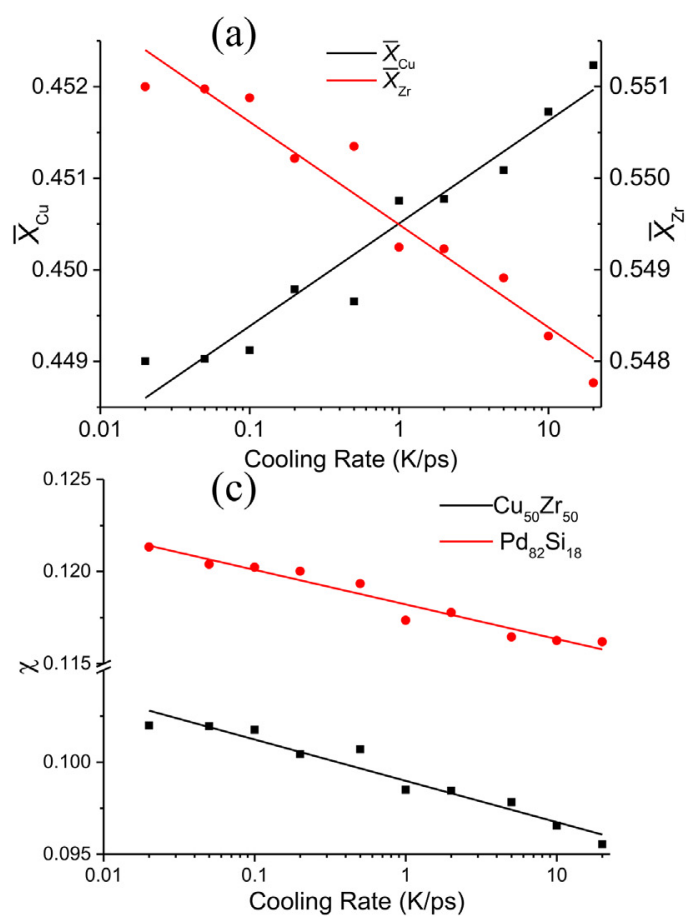

In this way, the CSRO as a function of cooling rates is plotted in Fig. 2 (c) for both $\mathrm{Pd}_{82} \mathrm{Si}_{18}$ and $\mathrm{Cu}_{50} \mathrm{Zr}_{50}$, respectively. It indicates that CSRO of a system decreases with increasing cooling rates. In addition, the correlation between CSRO (characterized by the value of $\chi$ ) and susceptibility of shear bands ( showing by $\Delta \tau$ ) is plotted in Fig. 2(d). On one hand, it clearly leads to a main conclusion that shear banding susceptibility increases with increasing level of CSRO in both $\mathrm{Pd}_{82} \mathrm{Si}_{18}$ and $\mathrm{Cu}_{50} \mathrm{Zr}_{50}$ system. On the other hand, for different systems, $\mathrm{Pd}_{82} \mathrm{Si}_{18}$ is of higher level of CSRO and consequently has larger stress overshoot, which denotes higher shear banding susceptibility. It is therefore we conclude that CSRO is one of the main causes behind the shear banding of glasses.

It is seen that the surrounding environments of Pd and Si atoms are quite different from each other in the $\mathrm{Pd}_{82} \mathrm{Si}_{18}$ system. As a result, the key question is that what the correlation between CSRO and atomic structure is, since in the common sense the latter directly determines the mechanical properties in MGs [35,36]. To further describe the local structural features, we focus on the nearest-neighbor $\mathrm{CN}$ and the dominating clusters characterized by the Voronoi index [37,38]. Several features are noticed from Fig. S2(a)-(f). (i) The distribution of CN of Pdcentered clusters and Si-centered clusters in $\mathrm{Pd}_{82} \mathrm{Si}_{18}$ is more discrete than that of $\mathrm{Cu}_{50} \mathrm{Zr}_{50}$. (ii) The packing structures around $\mathrm{Cu}$ and $\mathrm{Si}$ atoms have more dominating characteristic Voronoi index when compared with $\mathrm{Zr}$ and $\mathrm{Pd}$ atoms. (iii) $\mathrm{Cu}$-centered clusters in $\mathrm{Cu}_{50} \mathrm{Zr}_{50}$ and Si-centered clusters in $\mathrm{Pd}_{82} \mathrm{Si}_{18}$ are more regular and dominated by a characteristic type of Kasper polyhedron [24,39] like $\langle 0,0,12,0\rangle$, $\langle 0,2,8,2\rangle$ etc. Obviously, all the three phenomena are related to the chemical components and thus we can draw a conclusion that CSRO goes hand-in-hand with topological short-range order (TSRO) in amorphous alloys. Indeed, when CSRO increases, there is concurrent topological ordering going on. It could be the hidden rule underlying the mechanical properties like shear banding in metallic glasses.

Moreover, it is clear that the difference between $\mathrm{Cu}$-centered clusters and $\mathrm{Zr}$-centered clusters is quite smaller than that of $\mathrm{Pd}$ and $\mathrm{Si}$, which is consistent with the diversity of CSRO. In $\mathrm{Pd}_{82} \mathrm{Si}_{18}$, Pd atoms mainly form Pd-Pd metallic bonds with surrounding Pd atoms, while $\mathrm{Si}$ atoms tend to form Pd-Si covalent bonds with surrounding Pd
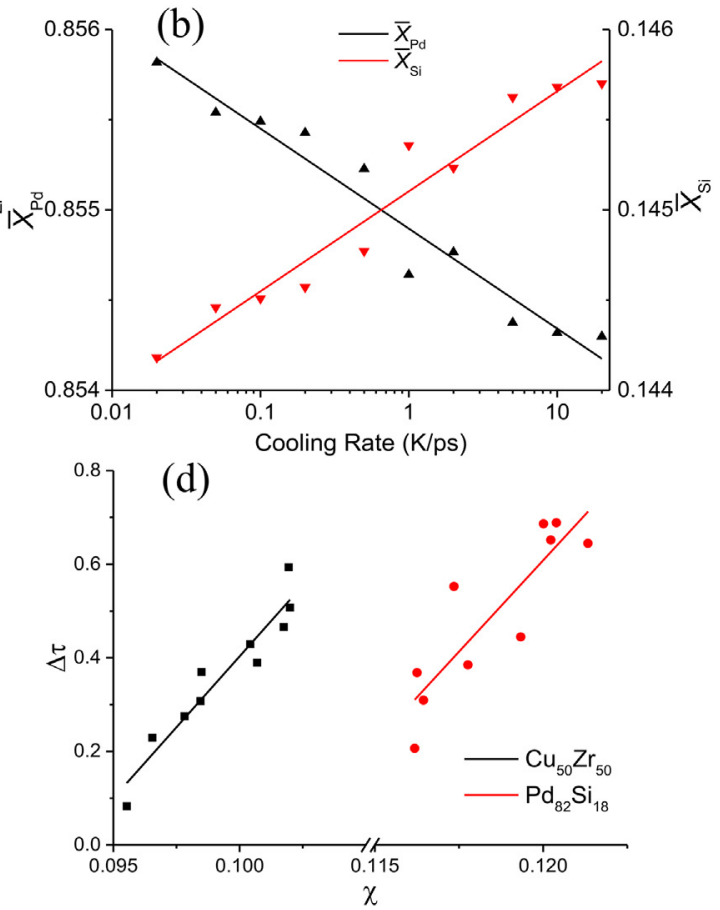

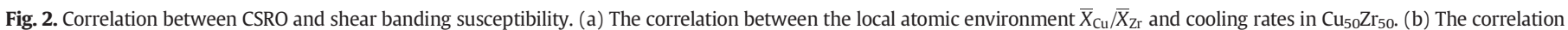

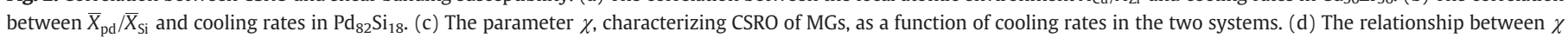
(CSRO) and $\Delta \tau$ (susceptibility of shear bands) in the two systems. 


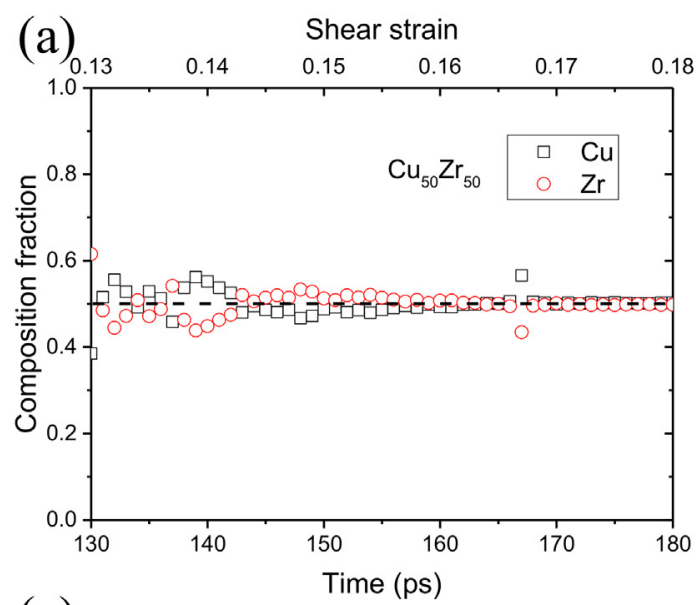

(c)

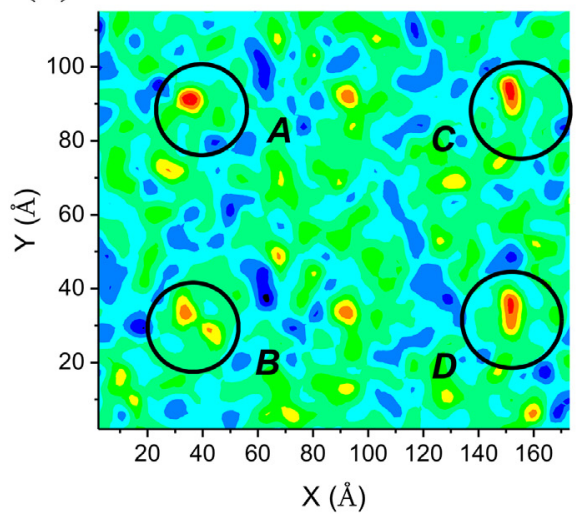

(b) Shear strain

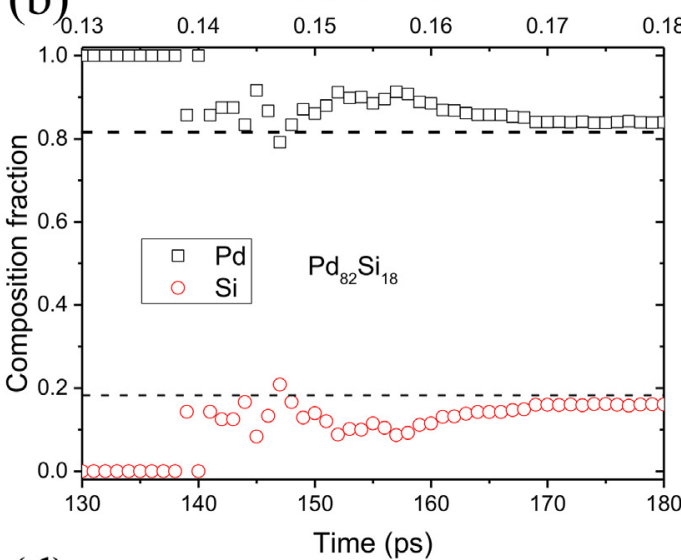

(d)
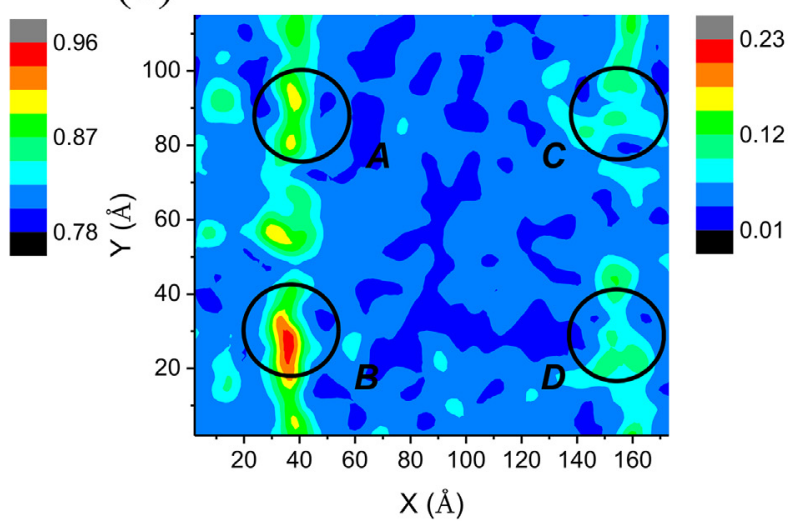

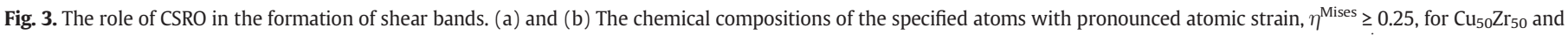

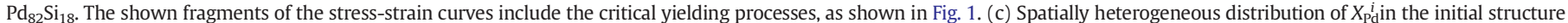

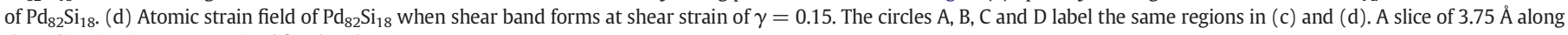
the $z$ direction is coarse-grained for the plot.

atoms according to the data listed in Table S1. Thus Si-centered clusters, as shown in Fig. S2(f), are more regular, denser, and more resistant to deformation than Pd-centered clusters; while this difference is not that significant in $\mathrm{Cu}_{50} \mathrm{Zr}_{50}$. Thus we expect STZs activation would initiate from Pd-rich regions, making the formation of shear bands strongly depends on CSRO. However, there would be no such obvious chemical trend in $\mathrm{Cu}_{50} \mathrm{Zr}_{50}$. This expectation is confirmed by our analysis of activated atoms. We trace the specified atoms which have undergone a large deformation $\left(\eta^{\text {Mises }} \geq 0.25\right)$ and analyze the composition of the traced atoms for both $\mathrm{Cu}_{50} \mathrm{Zr}_{50}$ and $\mathrm{Pd}_{82} \mathrm{Si}_{18}$, as shown in Fig. 3(a) and (b). In particular, the fraction of Pd atoms in the traced atoms is nearly $100 \%$ before $t=140 \mathrm{ps}$ (the moment when the shear band is about to form) and then begin to fluctuate. Then with the STZs percolation and shear band formation, the fraction of Pd atoms gradually tends to the value of the macroscopic fraction marked as the dashed line in Fig. 3 (b). In contrast, there is no clear trend to show which type of atom bears more atomic strain in $\mathrm{Cu}_{50} \mathrm{Zr}_{50}$; see Fig. 3(a).

In order to intuitively reflect the dependence of shear bands on CSRO and further prove our speculations, the spatially heterogeneous distribution of $X_{\mathrm{Pd}}^{i}$ in the initial structure of $\mathrm{Pd}_{82} \mathrm{Si}_{18}$ and the strain filed when the shear band forms are given in Fig. 3(c) and (d). Obviously, the formation of shear bands is affected by the distribution of the initial $X_{\mathrm{Pd}}^{i}$ content of the sample. In the initial sample, the distribution of $X_{\mathrm{Pd}}^{i}$ is quite inhomogeneous. During the shear process, STZs are more likely to be activated in the higher $X_{\mathrm{Pd}}^{i}$ regions (related to Pd-rich region) like the circled regions labeled by marks A, B, C and D in Fig. 3(c). As deformation goes on, shear localization is gradually accumulated in these regions and eventually form shear bands through the whole sample as shown in Fig. 3(d).
In conclusion, MD simulations and atomic structure analysis reveal that CSRO promotes shear banding susceptibility of metallic glasses. The $\mathrm{Pd}_{82} \mathrm{Si}_{18}$ system, with higher level of CSRO is more likely to form shear bands in contrast with $\mathrm{Cu}_{50} \mathrm{Zr}_{50}$, which has less CSRO. In addition, STZs activation would initiate from the Pd-rich regions which makes the formation of shear bands strongly dependent on CSRO while there would be no such obvious chemical trend in $\mathrm{Cu}_{50} \mathrm{Zr}_{50}$. Last but not least, the effect of CSRO on shear banding in metallic glasses goes hand-in-hand with the influence of TSRO. Due to CSRO, the surrounding structural environment and dominant polyhedron centered on Pd atoms are quite different from those of Si atoms. Thus Si-centered clusters are more regular, denser, more stable and more resistant to deformation than Pd-centered clusters. This is the structural explanation that how CSRO promotes the susceptibility of shear banding in metallic glasses.

\section{Acknowledgement}

This work is financially supported by the National Key Research and Development Program of China (No. 2017YFB0702003), the NSFC (No. 11472287, No. 11790292 and No. 11672299), the Strategic Priority Research Program (No. XDB22040302 and No. XDB22040303), the Key Research Program of Frontier Sciences (Grant No. QYZDJSSW-JSC011), and the Youth Promotion Association of Chinese Academy of Sciences.

\section{Appendix A. Supplementary data}

Supplementary data to this article can be found online at https://doi. org/10.1016/j.scriptamat.2018.11.001. 


\section{References}

[1] C.A. Schuh, T.C. Hufnagel, U. Ramamurty, Acta Mater. 55 (2007) 4067-4109.

[2] W.H. Wang, C. Dong, C.H. Shek, Mater. Sci. Eng. R. Rep. 44 (2004) 45-90.

[3] J. Schroers, W.L. Johnson, Phys. Rev. Lett. 93 (2004) 20-23.

[4] O.V. Kuzmin, Y.T. Pei, J.T.M. De Hosson, Scr. Mater. 67 (2012) 344-347.

[5] Y.Q. Cheng, A.J. Cao, E. Ma, Acta Mater. 57 (2009) 3253-3267.

[6] W.H. Wang, Prog. Mater. Sci. 57 (2012) 487-656.

[7] W.F. Wu, Y. Li, C.A. Schuh, Philos. Mag. 88 (2008) 71-89.

[8] O.V. Kuzmin, Y.T. Pei, C.O. Chen, JT.M. De Hosson, Acta Mater. 60 (2012) 889-898.

[9] D. Rodney, A. Tanguy, D. Vandembroucq, Model. Simul. Mater. Sci. Eng. 19 (2011).

[10] N. Wang, J. Ding, F. Yan, M. Asta, R.O. Ritchie, L. Li, npj Comput. Mater. 4 (2018) $1-10$

[11] Q. An, K. Samwer, M.D. Demetriou, M.C. Floyd, D.O. Duggins, W.L. Johnson, W.A. Goddard, Proc. Natl. Acad. Sci. 113 (2016) 7053-7058.

[12] M.Q. Jiang, L.H. Dai, J. Mech. Phys. Solids 57 (2009) 1267-1292.

[13] A. Bhattacharyya, G. Singh, K. Eswar Prasad, R. Narasimhan, U. Ramamurty, Mater. Sci. Eng. A 625 (2015) 245-251.

[14] L.H. Dai, Y.L. Bai, Int. J. Impact Eng. 35 (2008) 704-716.

15] A. Hirata, P. Guan, T. Fujita, Y. Hirotsu, A. Inoue, A.R. Yavari, T. Sakurai, M. Chen, Nat Mater. 10 (2011) 28-33.

[16] Z.L. Tian, Y.J. Wang, Y. Chen, L.H. Dai, Phys. Rev. B 96 (2017) 1-10.

[17] F. Shimizu, S. Ogata, J. Li, Mater. Trans. 48 (2007) 2923-2927.

18] F. Shimizu, S. Ogata, J. Li, Acta Mater. 54 (2006) 4293-4298.

[19] W. Li, H. Bei, Y. Tong, W. Dmowski, Y.F. Gao, Appl. Phys. Lett. 103 (2013) 0-5.
[20] J. Ding, S. Patinet, M.L. Falk, Y. Cheng, E. Ma, Proc. Natl. Acad. Sci. 111 (2014) 14052-14056

[21] A.S. Argon, Acta Metall. 27 (1979) 47-58.

[22] M.L. Falk, J.S. Langer, Phys. Rev. E Stat. Phys. Plasmas Fluids Relat. Interdiscip. Topics 57 (1998) 7192-7205.

[23] F. Boioli, T. Albaret, D. Rodney, Phys. Rev. E 95 (2017) 1-10.

[24] Y.Q. Cheng, E. Ma, Prog. Mater. Sci. 56 (2011) 379-473.

[25] Y.Q. Cheng, J. Ding, E. Ma, Res. Lett. 1 (2013) 3-12.

[26] S. Plimpton, J. Comput. Phys. 117 (1995) 1-19.

[27] Y.Q. Cheng, E. Ma, H.W. Sheng, Phys. Rev. Lett. 102 (2009) 1-4.

[28] H. Kozachkov, J. Kolodziejska, W.L. Johnson, D.C. Hofmann, Intermetallics 39 (2013) 89-93.

[29] M. Parrinello, A. Rahman, J. Appl. Phys. 52 (1981) 7182-7190.

[30] S. Nosé, J. Chem. Phys. 81 (1984) 511-519.

[31] W.G. Hoover, Phys. Rev. A 31 (1985) 1695-1697.

[32] Y.J. Wang, M.Q. Jiang, Z.L. Tian, L.H. Dai, Scr. Mater. 112 (2016) 37-41.

[33] M.Q. Jiang, G. Wilde, L.H. Dai, Mech. Mater. 81 (2015) 72-83.

[34] Y.Q. Cheng, A.J. Cao, H.W. Sheng, E. Ma, Acta Mater. 56 (2008) 5263-5275.

[35] W. Li, Y. Gao, H. Bei, Sci. Rep. 5 (2015) 1-15.

[36] X. Huang, Z. Ling, Y.J. Wang, L.H. Dai, Intermetallics 75 (2016) 36-41.

[37] L. Berthier, G. Biroli, Rev. Mod. Phys. 83 (2011) 587-645.

[38] D.R. Nelson, P.J. Steinhardt, Phys. Rev. Lett. 62 (1989) 978.

[39] F.C. Frank, J.S. Kasper, Acta Crystallogr. 11 (2010) 184-190. 